\title{
MANFAAT STANDAR DIAGNOSA KEPERAWATAN \\ DALAM PELAYANAN KESEHATAN
}

\section{Calita Elytisia Monica Ginting}

calitaelytisia11@gmail.com

\section{LATAR BELAKANG}

Diagnosa keperawatan merupakan salah satu tahap dari asuhan keperawatan dalam pelayanan kesehatan di rumah sakit.Diagnosa keperawatan dapat terlaksana,jika tahap sebelumnya (pengkajian keperawatan) telah dilakukan.Diagnosa keperawatan memberikan dasar untuk membuat dan menentukan intervensi yang diperlukan dalam mencapai hasil yang tepat.

Diagnosa keperawatan adalah penilaian atau pernyataan terhadap perubahan status kesehatan pasien berdasarkan data yang telah ada.Diagnosa keperawatan dapat ditegakkan dan menghasilkan keakuratan apabila didukung oleh kemampuan berpikir kritis seorang perawat dalam menganalisis data yang tersedia.

Perawat merupakan seseorang yang memiliki peran penting dalam pemberian asuhan keperawatan.Peran perawat tidak hanya mempengaruhi dan menentukan kualitas kesehatan pasien saja,tetapi juga mutu pelayanan kesehatan.Perawat harus mampu menegakkan standar diagnosa keperawatan berdasarkan respon pasien terhadap masalah kesehatannya.Perawat harus lebih memperhatikan proses kesehatan yang berlangsung pada klien saat tahap pengkajian agar mempermudah perumusan diagnosa keperawatan.Syarat perumusan diagnosa keperawatan yaitu mempunyai pengetahuan yang dapat membedakan antara sesuatu yang actual,risiko,dan potensial dalam diagnosa keperawatan.

Untuk menerapkan standar diagnosa keperawatan dalam pelayanan kesehatan,perawat perlu mengikuti pelatihan guna menghindari terjadinya kesenjangan.Karena apabila kesenjangan terjadi dalam mendiagnosa, maka akan berdampak kepada pasien.Pasien akan menerima intervensi yang salah dan mengalami peningkatan masa perawatan serta biaya perawatan.

Sebagai upaya dalam meningkatkan standar diagnosis keperawatan,maka diperlukan sikap yang benar dalam pengambilan keputusan.Sikap merupakan kesediaan untuk bertindak atau kesiapan dan bukan motif tertentu dari pelaksanaan.Sikap dibentuk berdasarkan pada pengalaman serta latihan sepanjang perkembangan individu,bukan dibawa sejak lahir.Sikap 
yang baik cenderung akan melakukan pendiagnosisan sesuai standar.Hal ini sudah menjadi tanggung jawab perawat dalam penentuan diagnosis yang terstandar.

Manfaat standar diagnosa keperawatan dalam pelayanan kesehatan ialah meningkatkan mutu pelayanan dan memelihara hubungan kerja yang efektif dengan semua kalangan kesehatan.

\section{TUJUAN}

Untuk mengetahui proses standar diagnosa keperawatan guna tercapainya hasil yang akurat dan mampu menentukan tindakan selanjutnya.

\section{METODE}

Metode yang digunakan dalam kajian ini adalah membaca dan menganalisis beberapa sumber yang berkaitan dengan diagnosa keperawatan berdasarkan hasil pencarian dari jurnal,buku teks,dan e-book dengan minimal 10 dan tahun paling tua 2012.

\section{HASIL}

Berdasarkan hasil pencarian dari beberapa sumber seperti jurnal,buku teks,dan e-book, didapatkan bahwa dalam menentukan diagnosa keperawatan perlu mengetahui komponenkomponen diagnosa,proses pengumpulan data,dan pengambilan keputusan agar memberikan kepuasan terhadap penerima pelayanan kesehatan (pasien).

Berdasarkan hasil pengumpulan data,perawat dapat mengidentifikasi masalah kesehatan pasien dengan sistematis.Pengumpulan data yang lengkap sangat mempengaruhi adanya masalah atau tidak dengan kondisi pasien.

Selanjutnya,dalam pengambilan keputusan,perawat akan mengambil keputusan sesuai batas wewenangnya sebagai perawat.Pengambilan keputusan harus berdasarkan pemikiran dan analisis yang tajam dan kritis.

Semua diagnosa keperawatan harus di dukung oleh data.Data yang sudah ada harus dilakukan analisis,dengan cara pengelompokan dan interpretasi data agar penegakan diagnosa dapat diterapkan dalam pelayanan kesehatan.

Penegakan diagnosa merupakan aspek penting dalam praktik keperawatan. Sistem penegakan diagnosis yang ideal harus memberikan informasi klien yang komprehensif,menunjukkan hasil dan standar klien ,memfasilitasi reimbursement dari pemerintah dan dari perusahaan 
asuransi pembayar,serta berfungsi sebagai dokumen legal (Twardon dan Gartner,1993 : Potter \& Perry ;2009)

Tanpa terminologi dan indikator yang terstandarisasi,penegakan diagnosis keperawatan menjadi tidak seragam,tidak akurat dan ambigu sehingga menyebabkan ketidaktepatan pengambilan keputusan dan ketidaksesuaian asuhan keperawatan yang diberikan kepada pasien.

\section{PEMBAHASAN}

Diagnosa keperawatan merupakan aspek penting dalam pelayanan kesehatan.Diagnosa keperawatan adalah dasar pengembangan rencana intervensi yang ditangani oleh perawat.Diagnosa keperawatan dapat memberikan intervensi secara pasti untuk mengurangi atau mencegah terjadinya masalah.Pemilihan diagnosa keperawatan yang benar berdasarkan pengkajian membutuhkan keahlian diagnostik (yaitu kemampuan untuk membuat keputusan yang cepat dan akurat dari data pasien).(Cho et al.,2010).Ada beberapa hal yang harus diketahui sebelum menentukan diagnosa keperawatan,diantaranya ialah :

\section{Pengertian Diagnosa Keperawatan}

Diagnosa keperawatan adalah penilaian klinis terhadap respons individu terkait kondisi kesehatannya oleh perawat, yang dapat membantu individu tersebut mencapai kesehatan yang optimal.

\section{Karakteristik Diagnosa}

Hal yang menjadi karakteristik diagnosa ialah indikator klinis.Indikator klinis merupakan tanda dan gejala objektif atau subjektif yaitu tanda yang menggambarkan tingkah laku pasien,baik berdasarkan observasi perawat maupun yang dikatakan oleh pasien/keluarga.

\section{Komponen Diagnosa}

Komponen diagnosa keperawatan terdiri atas :

a. Problem

Masalah (problem) merupakan pernyataan tentang perubahan yang tidak menguntungkan,yang terjadi pada pasien terkait kondisi kesehatannya. 


\section{b. Etiologi}

Etiologi merupakan pernyataan tentang penyebab perubahan yang tidak menguntungkan pada kondisi kesehatan pasien.

c. Sign

Sign merupakan tanda yang menggambarkan masalah dan penyebab dari perubahan kondisi kesehatan pasien.

Maka,dapat dinyatakan bahwa problem berhubungan dengan etiologi ditandai dengan sign.Ketiga hal tersebut sangat berkaitan.

\section{Penerapan Proses Pengumpulan Data}

Pengumpulan data adalah pengumpulan informasi berdasarkan fakta .Proses yang dilakukan dalam pengumpulan data dapat berupa :

a.Wawancara

Pengumpulan data dengan melakukan tanya jawab langsung kepada pasien atau keluarga pasien.

b. Observasi

Pengumpulan data dengan mengadakan pengamatan langsung terhadap hal-hal yang dianggap perlu dan berkaitan dengan kondisi kesehatan pasien.

\section{Proses Analisis Data}

Analisis data adalah Proses mengaitkan data dengan konsep,teori,ataupun prinsip yang relevan.Dalam menganalisis perlu memiliki daya berpikir dan penalaran yang kuat guna menentukan alternatif pemecahan masalah kesehatan pasien. Ada beberapa cara dalam menganalisis data yaitu :

\section{a. Pengelompokan Data}

Data-data pasien atau keadaan tertentu dimana pasien mengalami permasalahan kesehatan dikelompokkan berdasarkan kriteria permasalahannya. 


\section{b. Interpretasi Data}

Mengidentifikasi kelebihan dan masalah klien.Meninjau karakteristik atau faktor risiko,eliminasi yang tidak relevan,dan mengonfirmasi yang relevan.

\section{Proses Perumusan Masalah}

Dari analisis data ditemukan beberapa informasi yang berguna untuk merumuskan masalah .Masalah adalah kesenjangan yang terjadi dari apa yang "seharusnya" terjadi dan apa yang "nyata" terjadi.Dimana Hal yang "seharusnya" berupa standar,pedoman,teori,ataupun peraturan,dll.Sedangkan hal yang "nyata" berupa kenyataan yang terjadi saat itu.Proses perumusan masalah dapat menggunakan komponen diagnosa,ialah masalah (problem), penyebab (etiologi), dan gejala (symptom).

\section{Pengambilan Keputusan}

Pengambilan keputusan sangat penting dalam diagnosa keperawatan.Pengambilan keputusan adalah suatu pendekatan yang sistematis terhadap hakekat suatu masalah dengan pengumpulan fakta-fakta dan data.Dalam proses pengambilan keputusan ada hal yang perlu diperhatikan yaitu :

1.Tersedianya sumber-sumber untuk melaksanakan keputusan yang akan diambil

2. Pemecahan masalah harus didasarkan pada fakta-fakta yang terkumpul dengan sistematis

3. Keputusan yang diambil sudah dianalisa secara matang dari berbagai alternatif.

\section{Klasifikasi Diagnosa Keperawatan (SDKI NANDA)}

SDKI atau Standar Diagnosa Keperawatan Indonesia merupakan salah satu standard yang dibutuhkan dalam penyelenggaraan praktik keperawatan di Indonesia.

Tujuan SDKI ialah :

- Menjadi paduan atau acuan bagi perawat dalam menegakkan diagnosa keperawatan

- Meningkatkan otonomi perawat dalam memberikan pelayanan kesehatan

- Memudahkan komunikasi intraprofesional dan interprofesional dengan penggunaan istilah yang seragam dan terstandarisasi. 
Klasifikasi diagnosis keperawatan berdasarkan SDKI 2016 :

1 Fisiologi

- Respirasi

- Sirkulasi

- Nutrisi dan Cairan

- Aktivitas dan istirahat

- Neurosensori

- Reproduksi dan seksualitas

2. Psikologis

- Nyeri dan kenyamanan

- Integritas ego

- Pertumbuhan dan perkembangan

3. Perilaku

- Kebersihan diri

- Penyuluhan dan pembelajaran

4. Relasional

- Interaksi sosial

5. Lingkungan

- Keamanan dan proteksi

The North American Nursing Diagnosis Association (NANDA) adalah badan formal untuk meningkatkan,mengkaji kembali,dengan mengesahkan daftar terbaru dari diagnosis keperawatan yang digunakan oleh perawat praktisi.

Diagnosa keperawatan NANDA terdiri dari 3 jenis yaitu :

1.Diagnosis keperawatan berfokus pada masalah

Mendeskripsikan penilaian klinis mengenai respons manusia yang tidak diharapkan terhadap kondisi kesehatan/proses kehidupan yang terjadi pada individu,keluarga,atau komunitas.

2. Diagnosis keperawatan risiko

Penilaian klinis mengenai kerentanan individu,keluarga,atau komunitas dalam menghadapi berkembangnya respons terhdap kondisi kesehatan/proses kehidupan. 
3. Diagnosis keperawatan promosi kesehatan

Penilaian klinis mengenai motivasi dan keinginan pasien untuk meningkatkan kesejahteraan dan mengaktualisasi potensi kesehatan manusia.

\section{KESIMPULAN}

Keberhasilan perawat dalam penerapan standar diagnosa keperawatan di rumah sakit akan meningkatkan mutu pelayanan kesehatan.Oleh karena itu,sebagai perawat perlu memiliki sikap dan cara berpikir yang tepat agar dalam penentuan diagnosa keperawatan dapat dilakukan dengan mudah.

\section{SARAN}

Diharapkan dalam proses penentuan diagnosa keperawatan lebih memperhatikan teknik pengumpulan data dan pengelompokkan data agar dapat memberikan hasil yang optimal. 


\section{DAFTAR PUSTAKA}

DS Bambang Sudono,Dhani Setya A,dan Rif Atiningtyas H.2017. Gambaran Kemampuan Berpikir Kritis Perawat Primer Dalam Pelaksanaan Asuhan Keperawatan Di Rumah Sakit Islam Surakarta.Jurnal Ilmu Keperawatan , 10 (1) , 79-106.

Handini,Aviva,dan Milkhatun.2020.Hubungan Antara Status Pelatihan Proses Keperawatan Dengan Sikap Perawat Dalam Menerapkan Standar Diagnosis Keperawatan Indonesia Di Rumah Sakit Umum Daerah Pemerintah Samarinda.Borneo Student Research ,1 (3) ,15311536.

Harnilawati.2013.Konsep Dan Proses Keperawatan Keluarga.Sulawesi Selatan : Pustaka AS Salam.

Irman,Ode, Yosefin Nelista,dan Yosephina Maria Hawa Keytimu.2020.Buku Ajar Asuhan Keperawatan Pada Pasien Sindrom Koroner Akut.Jawa Timur : CV Penerbit Qiara Media.

Kusnadi,Elon.2017.Analisis Kelemgkapan Dokumentasi Keperawatan Di Ruang Rawat Inap Non Intensive Rumah Sakit X.Jurna Bidang Ilmu Kesehatan, 9 (1) ,553-562.

Muhith dan Abdul.2015.Pendidikan Keperawatan Jiwa.Yogyakarta : CV Andi Offset.

Noviestari,Enie dkk.2020.Dasar-Dasar Keperawatan Edisi Indonesia ke-9.Singapura : Elsevier.Vol 1.

Nujannnah Intansari,Dewi Retno Pamuungkas, dan Sri Warsini.2017.Perbandingan Antara Diagnosis Yang Sering Ditegakkan Dan Possible Diagnosis Yang Sering Diprediksikan Oleh Perawat Pada Klien Dengan Gangguan Jiwa.Jurnal Keperawatan Klinis Dan Komunitas, 1 (1) ,8-15.

Nuraini,Dwi,dan Mariyam.2020. Dampak Fisiologi Post Kemoterapi Pada Anak Limfositik Leukemia Akut.Ners Muda ,1 (2).

Rohmah,Nikmatur,dan Saiful Walid.2019.Proses Keperawatan Berbasis KKNI.Malang : Edulitera.

Sari,Selvia Harum,Agianto dan Abdurahman Wahid.2015.Batasan Karakteristik Dan Faktor yang Berhubungan (Etiologi) Diagnosa Keperawatan : Hambatan Mobilitas Fisik Pada Pasien Stroke.Batasan Karakteristik Dan Etiologi, 3 (1) , 12-21. 
Simamora, R. H., Bukit, E., Purba, J. M., \& Siahaan, J. (2017). Penguatan kinerja perawat dalam pemberian asuhan keperawatan melalui pelatihan ronde keperawatan di rumah sakit royal prima medan. Jurnal pengabdian kepada masyarakat, 23(2), 300-304.

Simamora, R. H. (2019). Socialization of Information Technology Utilization and Knowledge of Information System Effectiveness at Hospital Nurses in Medan, North Sumatra. Editorial Preface From the Desk of Managing Editor..., 10(9).

Supratti dan Ashriady.2016.Pendokumentasian Standar Asuhan Keperawatan Di Rumah Sakit Umum Daerah Mamuju,Indonesia.Jurnal Kesehatan MANARANG, 2 (1) , 44-51.

Suryono dan Christianto Nugroho.2020. Kompetensi Perawat Mendokumentasikan Diagnosis Keperawatan Indonesia (SDKI).Jurnal Ilmu Kesehatan, 11 (1), 233-238. 